\title{
Histochemical investigation of acid mucosubstances in secondary amyloidosis
}

\author{
C. A. PENNOCK, ${ }^{1}$ J. BURNS, AND G. MASSARELLA \\ From the Department of Pathology, Radcliffe Infirmary, Oxford
}

SYNOPSIS Sections of liver and spleen from six cases of secondary amyloidosis have been examined, by various improved histochemical methods, for acidic mucosubstances. The results indicate ais complex in amyloid deposits of protein and sulphated mucopolysaccharides in which the principal $\vec{G}$ substance is heparan sulphate with traces of chondroitin sulphates. Deposits also contain sialicor acid. The results are compared with chemical analyses of the same tissues and isolated fibrils which $\infty$ confirm the presence of heparan sulphate, chondroitin sulphates, and a sialic acid containing 9 protein.

Amyloid has been the subject of several extensive studies over many years. Electron microscope studies have revealed that amyloid has a fine fibrillar structure (Cohen and Calkins, 1959). A recent analysis of isolated fibrils (Cohen, 1966) has shown that amyloid contains only a small amount of uronic-acid-containing material whereas a chemical analysis of whole tissues reveals that there are increased amounts of sulphated mucopolysaccharides in amyloid-bearing organs (Bitter and Muir, 1966).

Braunstein and Beurger (1959) in their histochemical studies suggested that carboxylated polysaccharides are present rather than sulphated polysaccharides, while Clausen and Christensen (1964) have isolated hyaluronic acid from cardiac amyloid. Whether acid mucopolysaccharides are an integral part of the amyloid fibril or merely reflect alterations in the ground substance surrounding the fibrils remains unresolved.

Because of the recent introduction of improved histochemical techniques for the demonstration and differentiation of acid mucosubstances in tissue sections, it was considered worthwhile to investigate again the histochemistry of amyloid tissues.

\section{METHODS}

Formalin-fixed, deparaffinized sections of liver and spleen from six cases of secondary amyloidosis were subjected to the following histochemical procedures: $1 \%$ Alcian blue 8GX pH 2.5 (Mowry, 1960); 1\% Alcian blue $8 \mathrm{GX} p \mathrm{H} 1.0$ (Lev and Spicer, 1964); 0.1\% Alcian

${ }^{1}$ Present address: Department of Pathology, Bristol Royal Infirmary, Bristol, 2.

Received for publication 19 December 1967. blue $8 \mathrm{GX}$ pH 5.7 with added magnesium chloride $0.3, \frac{\mathrm{Z}}{\mathrm{C}}$ 0.7 , or $1.0 \mathrm{M}$ (Scott, Dorling, and Quintarelli, 1964); $\stackrel{\mathbb{Q}}{-}$ Alcian blue $(p \mathrm{H} \quad 2.5)$ - periodic-acid-Schiff reaction $\vec{\oplus}$ (Mowry and Winkler, 1956); aldehyde fuchsin (Spicer $\mathscr{D}$ and Meyer, 960); high iron diamine (Spicer, 1965); thioflavine T ( $p \mathrm{H} \mathrm{3.6)}$ (Vasser and Culling, 1959); thioflavine T ( $p \mathrm{H} \mathrm{1.0)}$ (Burns, Pennock, and Stoward, 1967).

Some of these histochemical techniques were also applied to sections which had been pre-treated by one of $\frac{O}{D}$ the following methods: pepsin digestion (Quintarelli et al, 1964); hyaluronidase digestion (Leppi and Stoward, $\overrightarrow{\vec{O}}$ 1965); sialidase digestion (Spicer and Warren, 1960); $\exists$ methylation and methylation followed by saponification (Spicer, 1960).

Appropriate control tissues were used throughout.

The sections were examined microscopically and the? intensity of the staining reactions was scored by one of $\frac{}{7}$ us (G.M.) without prior knowledge of which sections had been predigested, etc, before staining.

\section{RESULTS}

Amyloid deposits in different tissues showed slight variation in staining intensity when subjected to the $N$ same staining procedure. However, the results shown in Table I represent overall results and aO general pattern which is true for all deposits exam- $\omega$ ined. We found variation in staining and experienced difficulty in interpreting the results when sectionso were stained with Azur A, Toluidine blue, or by the periodic-acid-Schiff technique and excluded these ${ }^{+}$ methods from further study.

In the sections which had not been subjected to $\frac{\vec{\Phi}}{\mathbb{D}}$ any special treatment other than the histochemical $\stackrel{\square}{9}$ staining reactions themselves, the amyloid deposits 
were only clearly visible by the thioflavine T, Alcian blue $(p H 1.0)$ or Alcian blue with magnesium chloride reactions. The intensity of staining was increased when sections were predigested with pepsin. This was also true of the aldehyde fuchsin, Alcian blue ( $p \mathrm{H} 2.5)$, and high iron diamine reactions.

Alcianophilia was abolished at $p \mathrm{H} 2.5$ and reduced at $p \mathrm{H} 1.0$ or in the presence of magnesium chloride, when sections were treated with testicular hyaluronidase. Sections of liver from one case of amyloidosis failed to show this phenomenon.

All staining reactions were abolished in sections which had previously been methylated at $37^{\circ} \mathrm{C}$ for four hours (with the exception of thioflavine $\mathrm{T}$ when the reaction was only reduced after prolonged methylation). Sections saponified after methylation exhibited a weak positive staining with Alcian blue at $p \mathrm{H} 2.5$ and in $0.3 \mathrm{M}$ magnesium chloride.

\section{DISCUSSION}

Our results following pepsin digestion are in agreement with those of Windrum and Kramer (1957) in a study of metachromasia from which they concluded that protein present in amyloid blocked anionicbinding sites. With the exception of thioflavine $T$ and Alcian blue ( $p \mathrm{H} \mathrm{1.0)}$ the staining of amyloid deposits was very weak. However, when sections were digested with pepsin the intensity of staining was greatly increased. This was also true of those histochemical reactions which are generally accepted to be specific for sulphated mucosubstances, ie, aldehyde fuchsin, Alcian blue ( $p \mathrm{H} \mathrm{1.0)}$, and high iron diamine.

Alcian blue interacts with both carboxylated and sulphated structures (Quintarelli et al, 1964a). Alcianophilia of amyloid deposits at $p \mathrm{H} 1.0$ can only be accounted for by the presence of sulphated mucosubstances since glucuronic or sialic carboxyl groups are fully associated at this $p \mathrm{H}$. Similarly, the alcianophilia found in the presence of $0.7 \mathrm{M}$ magnesium chloride indicates the presence of sulphated material since polycarboxylates are not thought to bind alcian blue above $0.3 \mathrm{M}$ concentration of magnesium chloride (Scott and Dorling, 1965).

Methylation irreversibly esterifies sulphate groups whereas the reaction can be reversed by saponification in the case of carboxyl groups. The staining of methylated sections was not reactivated by saponification except those stained with Alcian blue at $p \mathrm{H} 2 \cdot 5$. These results suggest that sulphated mucosubstances are responsible for staining at low $p \mathrm{H}$, whereas the return of staining at $p \mathrm{H} 2.5$ after saponification suggests that carboxyl groups are also present. The approximate $p \mathrm{~K}$ of glucuronic carboxyls is $3 \cdot 1$ to $3 \cdot 3$, whereas the $p \mathrm{~K}$ of sialic acid is approximately $2 \cdot 3$ (Quintarelli et al, 1964b), thus Alcian blue staining at $p \mathrm{H} 2.5$ may be due to the latter.

The increase in dye uptake seen after pepsin digestion enabled us to examine the combined Alcian blue-PAS reaction of Mowry and Winkler (1965) for the simultaneous demonstrations of acidic substances and 1, 2 glycols in tissue sections. Amyloid deposits were coloured a moderately deep bluish purple which was reduced to a pink colour after sialidase digestion. These results also indicate the presence of sialic acid in amyloid material.

Digestion with testicular hyaluronidase, which will remove hyaluronic acid and chondroitin sulphates $A$ and $C$, reduced the intensity of alcianophilia at

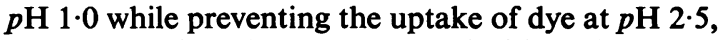
thus suggesting that some chondroitin sulphate $\mathbf{A}$ or $\mathrm{C}$ is removed and residual staining at low $p \mathrm{H}$ is due to chondroitin sulphate $B$ or heparan sulphate. The intensity of the remaining alcianophilia at $p \mathbf{H}$ 1.0 suggests that one of the latter substances is the major component in amyloid deposits.

The loss of alcianophilia at $p \mathrm{H} 2.5$ is unlikely to be due to removal of hyaluronic acid for the reason

TABLE I

RESULTS OF PRE-TREATMENT ${ }^{1}$

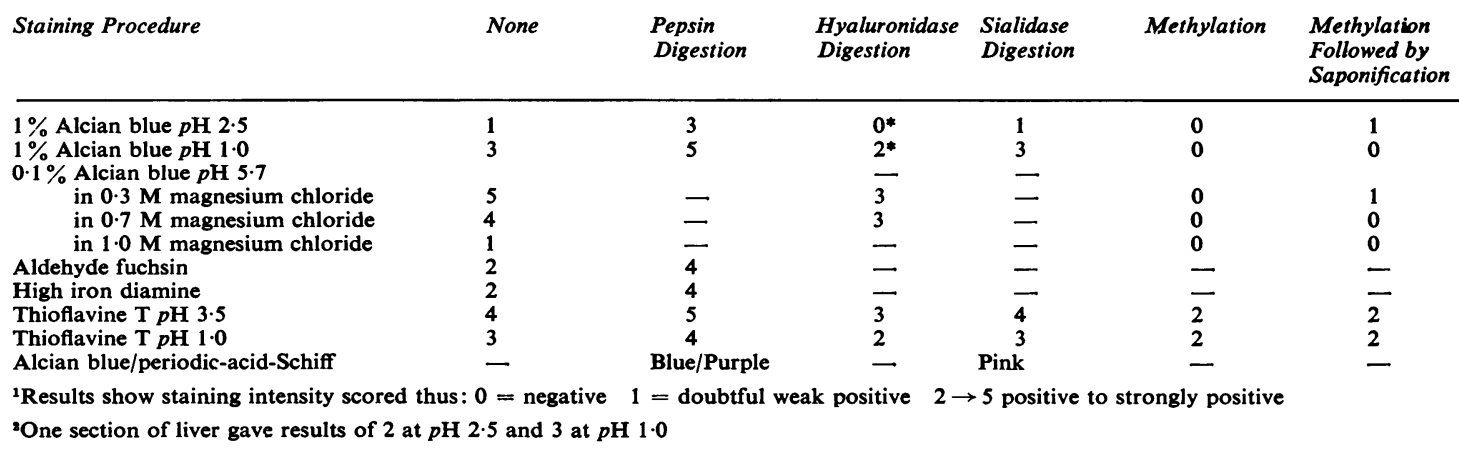


given in the discussion on the results of methylation. Furthermore, alcianophilia is reduced in the presence of $0.7 \mathrm{M}$ magnesium chloride.

The weak alcianophilia of amyloid deposits at $p \mathrm{H} 2.5$ has been observed by Braunstein and Buerger (1959) and Mowry and Scott (1967). The latter suggest that at this $p \mathrm{H}$ basophilia is affected by the presence of protein which blocks anionic binding sites. The increased basophilia at $p \mathrm{H} \mathrm{1.0}$ or in the presence of $0.3 \mathrm{M} \mathrm{Mg} \mathrm{Cl}$ at $p \mathrm{H} 5.7$ is thought to be due to high electrolyte concentration in both cases splitting the complex and increasing the availability of anionic binding sites. When we treat sections with pepsin before hyaluronidase digestion the sections exhibit alcianophilia at $p \mathrm{H} \mathrm{1.0,}$ 2.5 , and 5.7 which is only slightly reduced when compared with a pepsin-digested control. The degree of loss in staining intensity is the same, regardless of $p \mathrm{H}$, further supporting our view that hyaluronic acid is not involved in amyloid deposits whereas chondroitin sulphate $\mathrm{A}$ or $\mathrm{C}$, although not the major component, is present.

Results with thioflavine $T$ are less sharply defined than those with Alcian blue but they follow the same pattern. Burns et al (1967) have shown that thioflavine $T$ behaves in a similar manner to Alcian blue, forming a complex with acidic mucosubstances and at low $p H$ may complex with sulphated mucosubstances selectively. Interpretation of results with thioflavine $\mathrm{T}$ thus led us to the same conclusion as with Alcian blue; that amyloid deposits contain a sulphated mucopolysaccharide resistant to testicular hyaluronidase and therefore probably chondroitin sulphate B or heparan sulphate. In addition a small quantity of chondroitin sulphate $A$ or $C$ is present and there is evidence for the presence of sialic acid. We reach the same conclusions as Mowry and Scott (1967) who present a detailed study of the basophilia of amyloids, and from the effect of magnesium chloride on alcianophilia suggest that 'the critical electrolyte concentration pattern is more compatible with the presence of heparan sulphate than any other sulphated mucopolysaccharides'.

These results are at variance with the interpretation of Braunstein and Buerger (1959) who favoured the presence of carboxylated material. Their results are based on metachromasia which we have found difficult to interpret, particularly with regard to the effect of methylation and study of alcohol resistance. Results of metachromatic staining reactions may be open to interpretations different from those currently accepted.

Increased heparan sulphate content has been found in amyloid tissues by Meyer et al (1956), by Okuyama and Turumi (1963), and by Bitter and Muir (1966). Dr G. Manley kindly examined two of the livers used in this study and found approxi mately a ten-fold increase in sialic acid content and two to three-fold increase in uronic acid conten During experiments currently in progress, heparag sulphate and chondroitin sulphates have beem isolated from the tissues used in this study, the former in considerably increased amounts compare with normal control tissues, thus supporting ow cor histochemical findings (Pennock, 1968).

These results conflict with those of Clausen and Christensen (1964) who isolated hyaluronic acid from cardiac amyloid which may differ from other amy oids in composition (Benditt and Eriksen, 196ळ Analysis of fibrils isolated from the same tissues shows a low but constant content of uronic and sialic acids (Pennock, 1968), the results being in close agreement with those of Cohen (1966). Furthermore fibrils from one of our cases have been examined by Nichols and Clamp (1967) whoobtained analytical data also in close agreement with that of Cohenp (1966). They found two protein components, one ric in neutral hexose whereas the other contained sial acid. Thus our histochemical results agree with the chemical analysis of the same tissues; indeed the liver in this study, which showed no reduction $\vec{i}$ alcianophilia when treated with hyaluronidase, wạ subsequently found to contain twice as muaty heparan sulphate as the other amyloid lives examined. We believe that the results reported here support the view that acid mucopolysaccharides are intimately involved in the formation of amylogi deposits and are worthy of more extensive study we are to understand fully the pathogenesis of th? curious disease.

We wish to thank Dr A. H. T. Robb-Smith, Director of Pathology, Radcliffe Infirmary, Oxford, for his interes in this work and the provision of laboratory facilities. Our thanks are also due to Dr G. Manley, Nuffiet Department of Biochemistry, Radcliffe Infirmary, Oxfor for results of uronic and sialic acid assays.

\section{REFERENCES}

Bitter, T., and Muir, H. (1966). J. clin. Invest., 45, 963.

Braunstein, H., and Buerger, L. (1959). Amer. J. Path., 35, 791. I Benditt, E. P., and Eriksen, N. (1966). Proc. nat. Acad. Sct. (Wash $55,308$.

Burns, J., Pennock, C. A., and Stoward, P. J. (1967). J. Path. Baç 94, 337.

Clausen, J., and Christensen, H. E. (1964). Acta path. microbiol. scand 60, 493.

Cohen, A. S. (1966). Lab. Invest., 15, 66.

-, and Calkins, E. (1959). Nature (Lond.), 183, 1202. Leppi, T. J., and Stoward, P. J. (1965). J. Histochem. Cytochem., 13

Lev, R., and Spicer, S. S. (1964). Ibid., 12, 309.

Meyer, K., Davidson, E., Linker, A., and Hoffman, P. (195 $\$ 9$ Biochim. biophys. Acta (Amst.), 21, 506.

Mowry, R. W. (1960). J. Histochem. Cytochem., 8, 323.

-, and Scott, J. E. (1967). Histochemie, 10, 8.

, and Winkler, C. H. (1956). Amer. J. Path., 2, 628.

Nichols, R. B., and Clamp, J. R. (1967). Clin. chim. Acta, 16, 415.

Okuyama, T., and Turumi, K. I. (1963). Ibid., 8, 140.

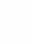


Pennock, C. A. (1968). Nature (Lond.), 217, 753

Quintarelli, G., Scott, J. E., and Dellovo, M.C. (1964a). Histochemie, 4,86 .

$\overline{4}, \frac{4,86 .}{1}$, (1964b). Ibid., 4, 99.

Scott, J. E., and Dorling, J. (1965). Ibid., 5, 221.
Spicer, S. S., and Meyer, D. B. (1960). Amer. J. clin. Path., 33, 453. , and Warren, L. (1960). J. Histochem. Cytochem., 8, 135. (1965). Ibid., 13, 211.

Vassar, P. S., and Culling, C. F. A. (1959). Arch. Path., 68, 487. Windrum, G. M., and Kramer, H. (1957). Ibid., 63, 373.

\section{The July 1968 Issue}

\section{THE JULY 1968 ISSUE CONTAINS THE FOLLOWING PAPERS}

Proteus and coliform meningoencephalitis in neonates W. R. SHORTLAND-WEBB

A study in vitro of the sensitivity to antibiotics of Bacteroides fragilis H. R. INGHAM, J. B. SELKON, A. A. CODD, and J. H. HALE

Septicaemia caused by Neisseria flavescens PAUL T. WERTLAKE and TEMPLE W. WILLIAMS, JR

An unusual Neisseria isolated from a case of meningitis P. W. KIPPAX, N. SAEED, AND W. A. V. PAMPLIN

Evaluation of a nitrite test kit (Stat-test) for the detection of significant bacteriuria J. T. LIE

Detection of bacteriuria in women attending local authority antenatal clinics using the dip-inoculum transport medium spoon method c. S. GOODWIN and AUDREY E. STEWART

The detection of circulating antibody in human toxocara infections using the indirect fluorescent antibody test B. BISSERU and A. W. WOODRUFF

Spongy degeneration of the white matter of the central nervous system associated with hyperglycinuria D. I. RUSHTON

Elastofibroma dorsi J. R. TIGHE, A. E. CLARK, and D. J. TURVEY

Elastofibroma D. H. MACKENZIE, J. F. WILSON, and K. B. COOKE

Neoplastic Paneth cells KLAUS LEWIN

Pulmonary blastoma A. J. BARSON, ALED W. JONES, and K. V. LODGE

Carcinoma of the lung and diffuse interstitial pulmonary fibrosis B. FOX and R. A. RISDON

Lymph node enlargement after a single massive infusion of iron dextran G. THEODOROPOULOS, A. MAKKOUS, and M. CONSTANTOULAKIS
Storage iron in 'muscle' J. D. TORRANCE, R. W. CHARLTON A. SCHMAMAN, S. R. LYNCH, and T. H. BOTHWELL

Ultrastructural study of liver in hepatic porphyria G. JEAN, G. LAMBERTENGHI, and T. RANZI

Complete suppression of haemoglobin A synthesis in haemoglobin D Los Angeles-beta thalassaemia A. J. MARENGO-ROWE, A. W. MCCRACKEN, P. FLANAGAN

Evaluation of discordant laboratory data in patients with thyroid disorders J. A. THOMSON, I. T. BOYLE, E. M. MCGIRR, E. M. MACDONALD, J. NICOL, and J. BROWN

Estimation of cerebrospinal fluid protein C. A. PENNOCK, L. P. PASSANT, and F. G. BOLTON

An evaluation of the Technicon AutoAnalyzer for automating complement-fixation tests C. E. D. TAYLOR, J. W. KERSHAW, AND G. V. HEIMER

\section{Technical methods}

Manual and automated methods for measuring urea based on a modification of its reaction with diacetyl monoxime and thiosemicarbazide ROBERT T. EVANS

Screening test for an automated protein-bound iodine technique S. G. WELSHMAN and G. MCKEE

Stability of papain-cysteine-anti-D mixture on freeze drying and on storage G. M. TODD

Use of a pancreatin-trypsin solution for the liquefaction of sputa for routine bacteriological examination G. A. RAWLINS

Letter to the Editor: Determination of haematocrit using the SMA4 A. E. GREEN and A. G. SIGNY

Book reviews

The Association of Clinical Pathologists: 80th general meeting

Copies are still available and may be obtained from the PUBLISHING MANAGER, BRITISH MEDICAL ASSOCIATION, TAVISTOCK SQUARF, W.C.1, price 18s. 6D. 